\title{
UK Renal Registry 16th Annual Report: Chapter 15 Epidemiology of Reported Infections amongst Patients Receiving Dialysis for Established Renal Failure in England from May 2011 to April 2012: a Joint Report from Public Health England and the UK Renal Registry
}

\author{
Lisa Crowley ${ }^{\mathrm{a}}$, David Pitcher ${ }^{\mathrm{b}}$, Jennie Wilson ${ }^{c}$, Rebecca Guy ${ }^{\mathrm{d}}$, Richard Fluck ${ }^{\mathrm{a}}$ \\ ${ }^{a}$ Royal Derby Hospital, Derby, UK; ${ }^{b}$ UK Renal Registry, Bristol, UK; ${ }^{c}$ Institute for Practice, Interdisciplinary Research and \\ Enterprise, University of West London, London, UK; ${ }^{d}$ Centre for Infectious Disease surveillance and Control, PHE, \\ London, UK
}

\section{Key Words}

Clostridium difficile - Eschericia coli - Dialysis - Established renal failure $\cdot$ Infection $\cdot$ Staphylococcus

\begin{abstract}
Introduction: Infection remains one of the leading causes of mortality in established renal failure patients receiving renal replacement therapy (RRT). Since 2007, centres providing RRT in England have been asked to provide additional data on patients with methicillin resistant Staphylococcus aureus (MRSA) bacteraemia. Since 2011, the option to provide data on methicillin sensitive Stapylococcus aureus (MSSA) and Escherichia coli bacteraemia, as well as Clostridium difficile infection has also been available. Methods: Data were submitted to Public Health England by laboratories via HCAI-DCS including whether the patients were receiving dialysis. Individual renal centres then confirmed the record either directly via the database or after being
\end{abstract}

contacted. Data were collected for the period of the 1st May 2011 to the 30th April 2012. Results: There were 49 episodes of MRSA bacteraemia, an overall rate of 0.22 per 100 dialysis patients per year, representing a further year on year fall in MRSA rate. There were a higher number of MSSA episodes, 322 in total, with an overall rate of 1.15 per 100 dialysis patients per year. The number of episodes and overall rate of E. coli and C. difficile were 284 and 0.92 per 100 prevalent dialysis patients per year and 172 and 0.61 per 100 prevalent dialysis patients per year respectively. In each infection type the presence of a central venous catheter appeared to correlate with an elevated risk. Conclusions: Data are presented from one year of infections reported to PHE. The rate of MRSA bacteraemia episodes in England continues to fall. There was a higher rate of MSSA infections amongst renal dialysis patients. Findings from the first year of $E$. coli and $C$. difficile data collection are also reported. Future cycles will give us a further idea of the trend in incidences of these infections.

$\begin{array}{ll}\text { KARGER } & \text { C 2014 S. Karger AG, Basel } \\ \begin{array}{l}\text { Fax +4161306 1234 } \\ \text { E-Mail karger@karger.com } \\ \text { www.karger.com }\end{array} & \begin{array}{l}\text { Accessible online at: } \\ \text { www.karger.com/nec }\end{array}\end{array}$

Lisa Crowley

UK Renal Registry, Southmead Hospital, Southmead Road, Bristol, BS10 5NB, UK

Email: renalregistry@renalregistry.nhs.uk 


\section{Introduction}

Infection remains the second leading cause of death in patients with established renal failure (ERF) who receive renal replacement therapy (RRT). The high rates of systemic infection reported in haemodialysis patients are related to their impaired immune system, the high number of invasive procedures they are exposed to and the type of vascular access used [1].

Previous UK Renal Registry (UKRR) reports have detailed the epidemiology of staphylococcal bacteraemias in patients with ERF receiving dialysis [2]. These were joint reports from the UKRR and the Health Protection Agency (HPA). As of 1st April 2013 the HPA has now become part of Public Health England (PHE) within the Department of Health. In addition to staphylococcal bacteraemias, surveillance has been expanded to incorporate Escherichia coli (E. coli) bloodstream infections (BSIs). As well as the mandatory reporting of methicillin resistant Staphylococcus aureus (MRSA) BSIs, methicillin sensitive Staphylococcus aureus (MSSA) BSIs have been mandatory to report since January 2011 and E. coli BSIs since June 2011; Clostridium difficile infection (CDI) reporting has been mandatory for all patients aged two and above since 2007. CDIs are reported according to a national testing protocol although during the timeframe of this report there may have been some inter-hospital variation in testing methods [2].

MRSA BSI surveillance is the only data collection of the four which displays a prompt for additional renal failure information although the unprompted feature is available for the other collections; however, completion of renal failure information is not a requirement for any of these data collections. The data is supplied by clinical staff and captured using a secure web-based system, the Healthcare Associated Infection Data Capture System (HCAI-DCS). As in previous reports, a final round of data validation was also undertaken which involved emailing the clinical or infection control leads at each centre in order for them to check the details and accept the record. The dataset included dialysis modality, type of dialysis access and use of non-tunnelled venous catheters within the preceding 28 days. The previous report confirmed that while dialysis patients remain at increased risk from MRSA there has been a continued year on year decline in the number of bacteraemias [3]. The report also provided the first experience of MSSA BSI reporting for the first six months of mandatory surveillance.

This report covers one year of reporting for MRSA, MSSA and CDI, and eleven months of reporting for
E. coli BSI, in patients with ERF who were receiving dialysis in England. This is the first UKRR report which will contain data on Clostridium difficile (C. difficile) and $E$. coli infections reported by laboratories as being associated with ERF patients receiving dialysis.

\section{Methods}

The report covers the period of 1st May 2011 to 30th April 2012. In choosing this time frame it is important to note that the data on MSSA reported here overlaps with the period included in the previous UKRR report where MSSA cases from January 2011 to June 2011 were reported.

It should also be noted that even though reporting is mandatory for these data collections (MRSA, MSSA and E. coli BSI and CDI) completion of renal failure and dialysis information is currently conducted on a voluntary basis depending on the data entry policy within the reporting NHS acute Trust. Therefore a reported infection rate of zero for an individual centre may represent a difference in reporting policy.

The methods used have been described in previous UKRR reports [4]. Briefly, four stages of data collection and validation were undertaken:

1 Identification of bacteraemias (and CDI) potentially associated with dialysis patients. This data was captured by the microbiology laboratory using the clinical details provided and the setting in which the sample was obtained.

2 This record was 'shared' with the parent renal centre. The microbiology laboratory attributed the record to the renal centre responsible for the dialysis of the patient which in turn triggered an email alert to the identified contact within the parent renal centre.

3 The renal centre then completed the additional renal data on the case via the HCAI-DCS website.

4 An additional validation and data capture step has been introduced as not all records were shared or completed. This involved emailing clinical or infection control leads at the parent centre to finish incomplete records and confirm that records associated with their centre were related to patients in ERF requiring dialysis.

This data reporting mechanism applies only to centres in England and is not utilised in Wales, Scotland or Northern Ireland.

For each infection, the number of individual episodes is shown alongside centre-specific rates which were calculated using the number of prevalent dialysis patients according to 2011 data [5]. The collection period for E. coli BSIs was eleven months compared to twelve months of collection for the other infections. The rates presented for E. coli have been adjusted accordingly to show the rate per 100 prevalent dialysis patients per year. Data on the type of access in use at the time of infection was also provided. In order to adjust for variation in precision of estimated rate, the rate of bacteraemia/CDI per 100 prevalent dialysis patients per year has been plotted against the centre size in a funnel plot. This process has been repeated for each infection. In the case of 
MRSA a comparative box plot to demonstrate the overall trend is also included.

\section{Results}

\section{Methicillin resistant Staphylococcus aureus}

In total, 53 MRSA bacteraemias were reported to PHE as being associated with a dialysis patient during the time frame of this report. Of these, four episodes were rejected by the parent centre because they occurred in patients with acute kidney injury (AKI) rather than the patient being in ERF. This left a total of 49 episodes of MRSA bacteraemia within the time period. These episodes were split between 42 patients registering one episode, two patients registering two episodes and one patient registering three infection episodes.

The overall infection rate for England was 0.22 per 100 prevalent dialysis patients per year. This rate represents a further year on year fall in the MRSA bacteraemia rates in England as illustrated by the box plot in figure 15.1. Centre level data can be seen in table 15.1 and includes the absolute number of episodes and rates based on using the number of 2011 dialysis patients as the denominator. The majority of centres did not report any MRSA bacteraemia episodes. Only two centres had an infection rate in excess of one per 100 prevalent dialysis patients per year (figure 15.2). In order to adjust for variation in precision of estimated rate, the rate has been plotted against centre size in a funnel plot (figure 15.3).

Amongst patients for whom the type of access at the time of infection was known, the highest proportion of infections occurred in patients with a tunnelled central

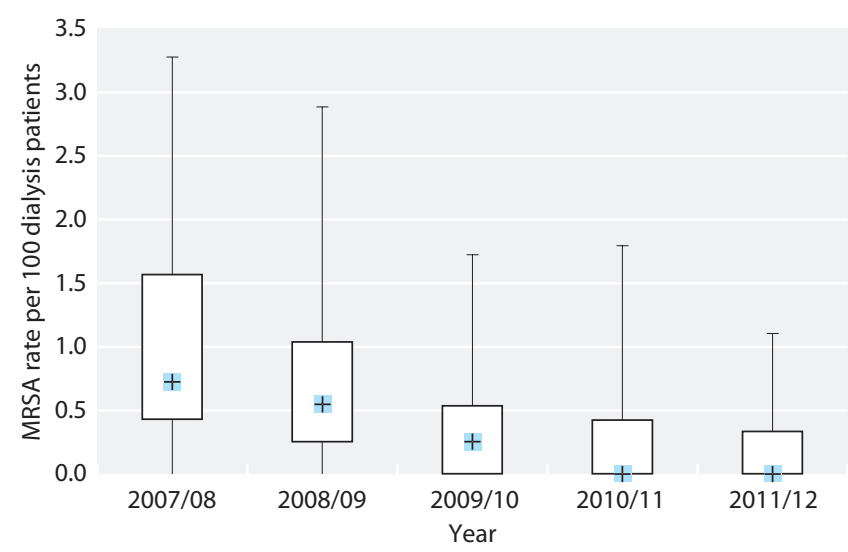

Fig. 15.1. Box and whisker plot of MRSA rates by renal centre per 100 prevalent dialysis patients per year by reporting year venous catheter (46.7\%). In total, $51.1 \%$ of cases occurred in patients with either a tunnelled or non-tunnelled catheter in situ, $8.9 \%$ of cases occurred in patients with an arteriovenous graft while $37.8 \%$ occurred in patients with an arteriovenous fistula (table 15.2).

\section{Clostridium difficile}

In total, 172 episodes of CDI were reported to PHE in the period covered by this report. Of these, only one episode was shared and completed in full. A further 26 episodes were shared of which two were rejected. Of the remaining unshared episodes, a further 32 were either rejected by the main centre or a main centre could not be identified. This left a total of 138 infections in dialysis patients giving a rate for England of 0.61 infections per 100 prevalent dialysis patients per year. Fourteen centres did not report any CDI episodes and the highest reported rate was 4.44 per 100 prevalent dialysis patients (table 15.3, figure 15.4). A funnel plot was created to display the rate compared to centre size (figure 15.5).

Amongst patients for whom the type of access was known, $49.5 \%$ of patients had a line at the time of the infection (47.4\% tunnelled catheter, $2.1 \%$ non-tunnelled catheter), $42.3 \%$ of patients had an arteriovenous fistula and $2.1 \%$ of patients an arteriovenous graft (table 15.4). Six (6.2\%) episodes occurred in peritoneal dialysis patients where access was via a Tenchkoff catheter.

\section{Methicillin sensitive Staphylococcus aureus}

In total, 322 episodes of MSSA bacteraemia were reported to PHE. However, 61 of these episodes were excluded leaving a final total of 261 bacteraemia episodes within the time frame. The main reasons for exclusion were a) the patient was unknown to the allocated centre and b) an inability to identify the centre responsible for the dialysis care. The majority of episodes were reported in haemodialysis patients, with just six reported episodes amongst peritoneal dialysis patients.

The overall MSSA bacteraemia rate for England was 1.15 per 100 prevalent dialysis patients per year. There was considerable variation in both the bacteraemia rate at each centre and also in the number of individual infection episodes at an individual centre which ranged from 0 to 25 (table 15.5). The highest rate reported was 3.83 per 100 prevalent dialysis patients per year (figure 15.6). Figure 15.7 is a funnel plot displaying the centre rates plotted against the size of the centre. A number of centres reported a zero infection rate. Centres reporting no MSSA infections are Birmingham Heartlands, Chelmsford, Nottingham, Plymouth, Ipswich, 
Table 15.1. Centre-specific data for MRSA bacteraemia episodes by access type, $1 / 05 / 2011$ to 30/04/2012

\begin{tabular}{|c|c|c|c|c|c|c|c|c|c|c|c|}
\hline \multirow[b]{2}{*}{ Centre } & \multicolumn{3}{|c|}{ Prevalent patients on $31 / 12 / 2011$} & \multicolumn{7}{|c|}{$\begin{array}{l}\text { MRSA bacteraemia episodes } \\
(1 / 5 / 2011-30 / 4 / 2012)\end{array}$} & \multirow{2}{*}{$\begin{array}{c}\text { Rate per } 100 \\
\text { dialysis } \\
\text { patients }\end{array}$} \\
\hline & HD & PD & Dialysis & Total & AVF & AVG & NTC & $\mathrm{TC}$ & PD & UK & \\
\hline B Heart & 446 & 46 & 492 & 0 & 0 & 0 & 0 & 0 & 0 & 0 & 0.00 \\
\hline $\mathrm{B} \mathrm{QEH}^{*}$ & 894 & 167 & 1,061 & 0 & 0 & 0 & 0 & 0 & 0 & 0 & 0.00 \\
\hline Basldn & 155 & 26 & 181 & 2 & 2 & 0 & 0 & 0 & 0 & 0 & 1.10 \\
\hline Bristol $^{*}$ & 474 & 66 & 540 & 1 & 0 & 0 & 0 & 0 & 0 & 1 & 0.19 \\
\hline Camb* & 371 & 41 & 412 & 0 & 0 & 0 & 0 & 0 & 0 & 0 & 0.00 \\
\hline Carlis & 66 & 24 & 90 & 0 & 0 & 0 & 0 & 0 & 0 & 0 & 0.00 \\
\hline Carsh & 753 & 103 & 856 & 3 & 0 & 0 & 0 & 3 & 0 & 0 & 0.35 \\
\hline Chelms & 119 & 26 & 145 & 0 & 0 & 0 & 0 & 0 & 0 & 0 & 0.00 \\
\hline Colchr & 120 & 0 & 120 & 0 & 0 & 0 & 0 & 0 & 0 & 0 & 0.00 \\
\hline Exeter & 376 & 78 & 454 & 0 & 0 & 0 & 0 & 0 & 0 & 0 & 0.00 \\
\hline Glouc & 194 & 39 & 233 & 0 & 0 & 0 & 0 & 0 & 0 & 0 & 0.00 \\
\hline Hull & 323 & 89 & 412 & 0 & 0 & 0 & 0 & 0 & 0 & 0 & 0.00 \\
\hline Ipswi & 125 & 31 & 156 & 1 & 0 & 0 & 0 & 0 & 0 & 1 & 0.64 \\
\hline Kent & 376 & 68 & 444 & 2 & 1 & 0 & 0 & 1 & 0 & 0 & 0.45 \\
\hline L Barts* & 899 & 171 & 1,070 & 0 & 0 & 0 & 0 & 0 & 0 & 0 & 0.00 \\
\hline L Guys* & 607 & 33 & 640 & 1 & 0 & 0 & 0 & 0 & 0 & 1 & 0.16 \\
\hline L Kings & 468 & 89 & 557 & 1 & 1 & 0 & 0 & 0 & 0 & 0 & 0.18 \\
\hline L Rfree* & 711 & 94 & 805 & 1 & 0 & 1 & 0 & 0 & 0 & 0 & 0.12 \\
\hline L St.G* & 294 & 55 & 349 & 1 & 0 & 0 & 0 & 1 & 0 & 0 & 0.29 \\
\hline L West* & 1,412 & 35 & 1,447 & 4 & 1 & 0 & 0 & 3 & 0 & 0 & 0.28 \\
\hline Leeds* & 513 & 92 & 605 & 2 & 0 & 1 & 0 & 1 & 0 & 0 & 0.33 \\
\hline Oxford* & 419 & 92 & 511 & 1 & 0 & 0 & 1 & 0 & 0 & 0 & 0.20 \\
\hline Plymth* & 132 & 47 & 179 & 0 & 0 & 0 & 0 & 0 & 0 & 0 & 0.00 \\
\hline Ports* & 524 & 95 & 619 & 1 & 0 & 0 & 0 & 1 & 0 & 0 & 0.16 \\
\hline Prestn & 520 & 65 & 585 & 4 & 2 & 0 & 0 & 1 & 0 & 1 & 0.68 \\
\hline Redng & 272 & 88 & 360 & 0 & 0 & 0 & 0 & 0 & 0 & 0 & 0.00 \\
\hline Salford & 363 & 113 & 476 & 0 & 0 & 0 & 0 & 0 & 0 & 0 & 0.00 \\
\hline Sheff* & 591 & 62 & 653 & 3 & 2 & 1 & 0 & 0 & 0 & 0 & 0.46 \\
\hline Shrew & 187 & 35 & 222 & 0 & 0 & 0 & 0 & 0 & 0 & 0 & 0.00 \\
\hline Stevng & 412 & 30 & 442 & 0 & 0 & 0 & 0 & 0 & 0 & 0 & 0.00 \\
\hline Sthend & 122 & 18 & 140 & 1 & 0 & 0 & 0 & 1 & 0 & 0 & 0.71 \\
\hline Stoke & 318 & 82 & 400 & 2 & 2 & 0 & 0 & 0 & 0 & 0 & 0.50 \\
\hline Sund & 178 & 17 & 195 & 2 & 0 & 0 & 0 & 1 & 1 & 0 & 1.03 \\
\hline Truro & 152 & 26 & 178 & 0 & 0 & 0 & 0 & 0 & 0 & 0 & 0.00 \\
\hline Wirral & 196 & 42 & 238 & 0 & 0 & 0 & 0 & 0 & 0 & 0 & 0.00 \\
\hline Wolve & 307 & 71 & 378 & 0 & 0 & 0 & 0 & 0 & 0 & 0 & 0.00 \\
\hline York & 144 & 25 & 169 & 0 & 0 & 0 & 0 & 0 & 0 & 0 & 0.00 \\
\hline England & 19,371 & 3,283 & 22,654 & 49 & 17 & 4 & 2 & 21 & 1 & 4 & 0.22 \\
\hline
\end{tabular}

*Transplant centres

$\mathrm{AVF}=$ arteriovenous fistula; $\mathrm{AVG}=$ arteriovenous graft; $\mathrm{NTC}=$ non-tunnelled catheter; $\mathrm{TC}=$ tunnelled catheter; $\mathrm{PD}=$ peritoneal dialysis; $\mathrm{UK}=$ unknown access type 


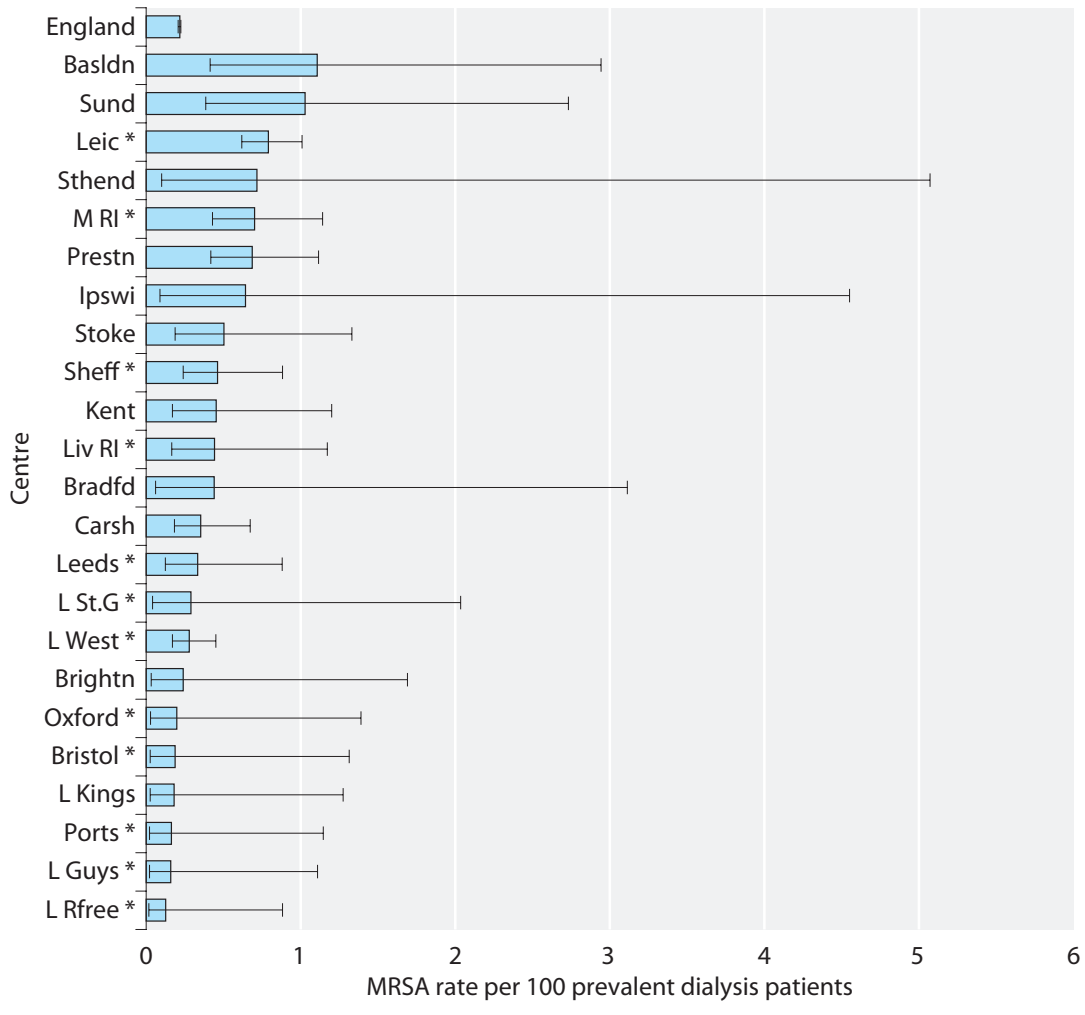

Fig. 15.2. MRSA bacteraemia rate per 100 prevalent dialysis patients per year by renal centre

Centres with no reported infection episodes are not displayed
Portsmouth and Reading. At present it is not clear whether this represents lack of reporting rather than no reportable episodes.

Amongst patients with an MSSA episode and for whom the type of access was known, a tunnelled catheter

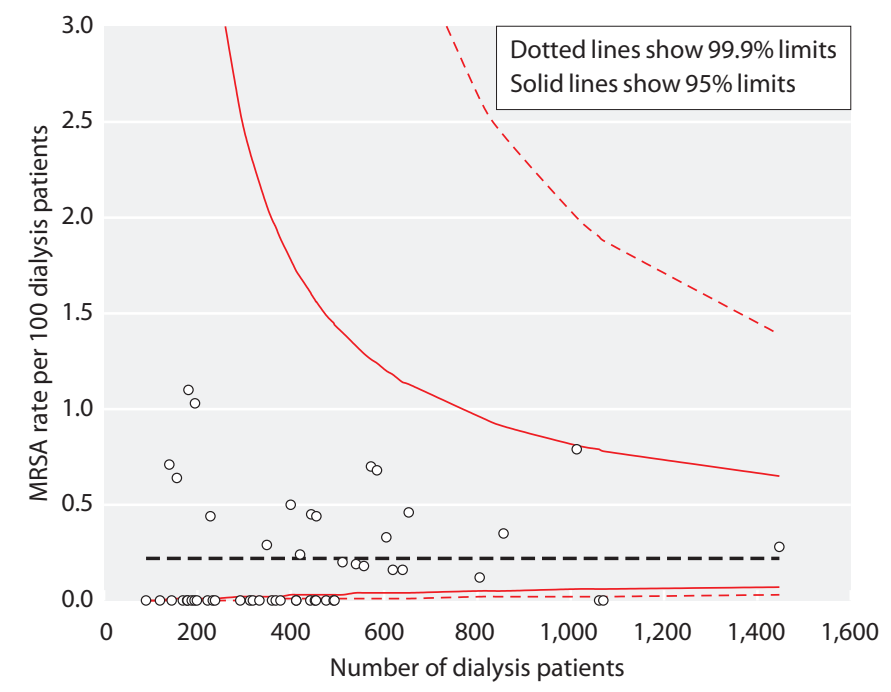

Fig. 15.3. Funnel plot of the MRSA bacteraemia rate per 100 prevalent dialysis patients per year by renal centre was in situ at the time of infection for $54.1 \%$ whilst $35.4 \%$ had a native arteriovenous fistula (table 15.6).

\section{Escherichia coli}

A total of 284 episodes of E. coli bacteraemia were reported in dialysis patients. A total of 93 episodes were excluded from the final total (the highest number of

Table 15.2. Type of renal access in patients with established renal failure where record shared and completed for the MRSA bacteraemia episodes

\begin{tabular}{lrrc}
\hline & \multicolumn{3}{c}{$\begin{array}{c}\text { MRSA bacteraemia } \\
(1 / 5 / 2011-30 / 4 / 2012)\end{array}$} \\
\cline { 2 - 4 } Renal access type & \multicolumn{1}{c}{$N$} & $\%$ & Access class \\
\hline Unknown & 4 & & \\
Haemodialysis & 0 & & \\
$\quad$ Other & 17 & 37.8 & 46.7 \\
$\quad$ Arteriovenous fistula & 4 & 8.9 & \\
$\quad$ Arteriovenous graft & 2 & 4.4 & 51.1 \\
$\quad$ Non-tunnelled catheter & 21 & 46.7 & 2.2 \\
$\quad$ Tunnelled catheter & 1 & 2.2 & 2.2 \\
Peritoneal dialysis & 49 & & \\
Total & $\mathbf{4 5}$ & & \\
Total known access & & & \\
\hline
\end{tabular}


Table 15.3. Centre-specific data for Clostridium difficile episodes by access type, $1 / 05 / 2011$ to 30/04/2012

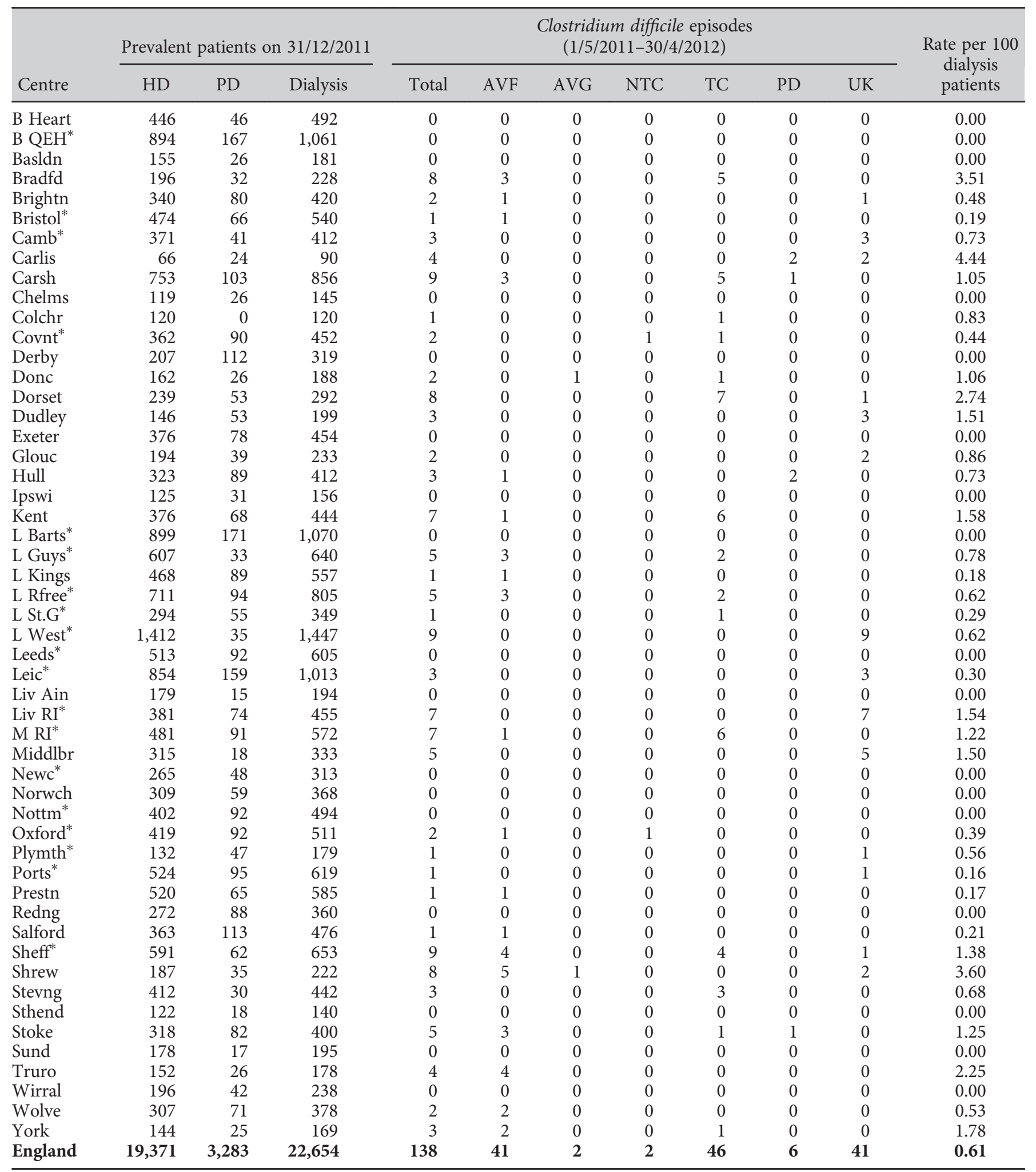

*Transplant centres

$\mathrm{AVF}=$ arteriovenous fistula; $\mathrm{AVG}=$ arteriovenous graft; $\mathrm{NTC}=$ non-tunnelled catheter; $\mathrm{TC}=$ tunnelled catheter; $\mathrm{PD}=$ peritoneal dialysis; $\mathrm{UK}=$ unknown access type 


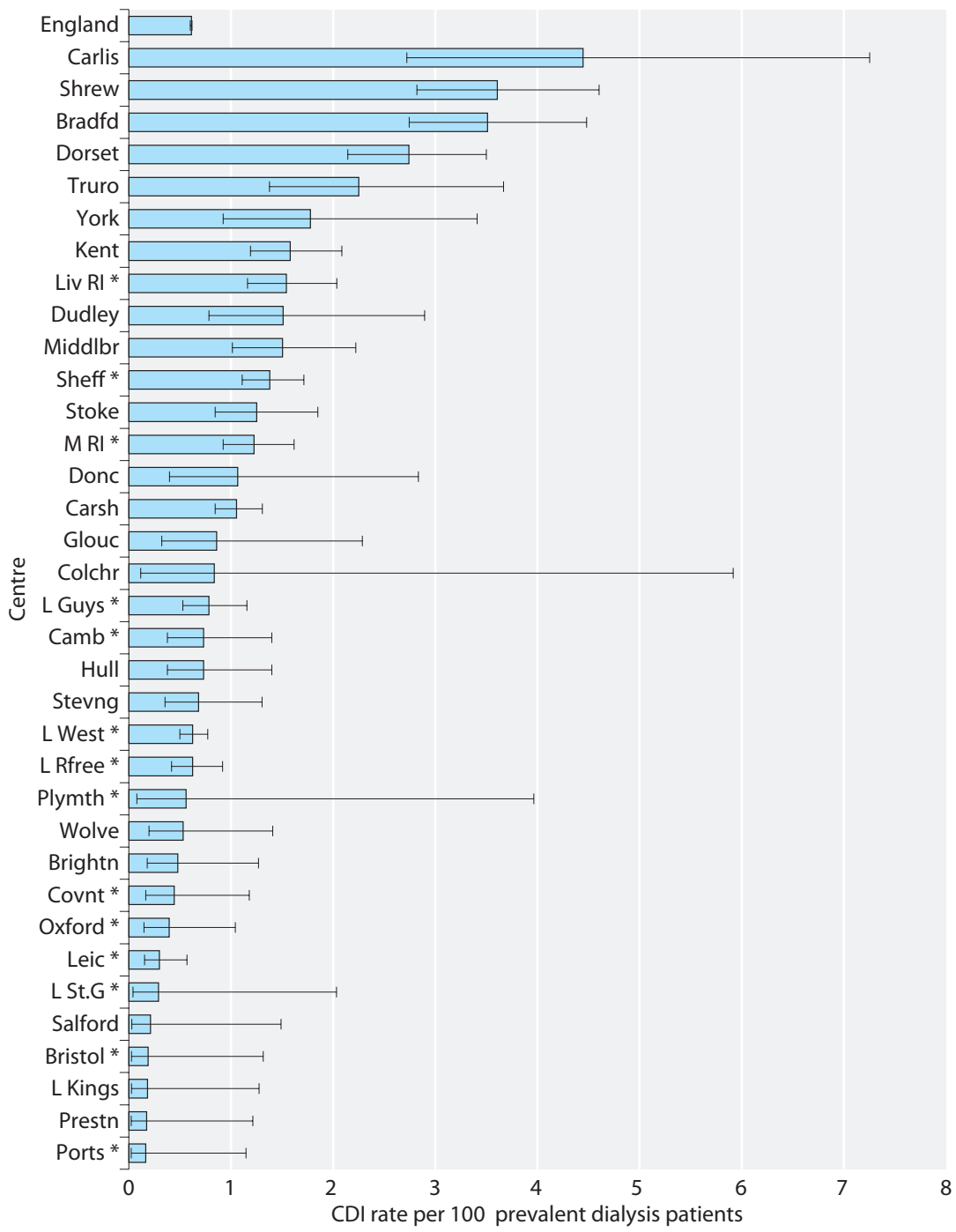

Fig. 15.4. CDI rate per 100 prevalent dialysis patients per year by renal centre Centres with no reported infection episodes are not displayed

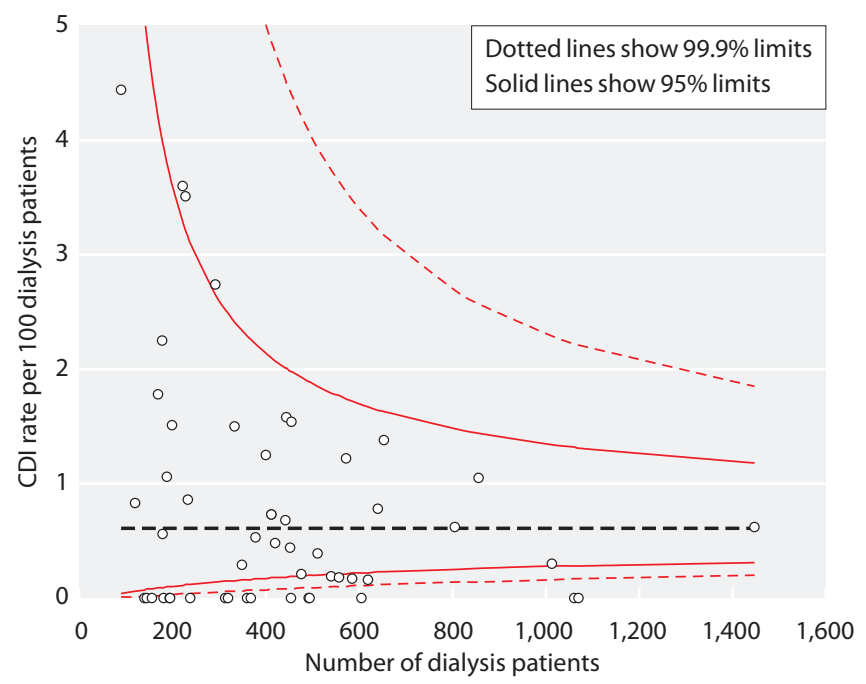

Fig. 15.5. Funnel plot of the CDI rate per 100 prevalent dialysis patients per year by renal centre
Table 15.4. Type of renal access in patients with established renal failure where record shared and completed for Clostridium difficile episodes

\begin{tabular}{lrrc}
\hline & \multicolumn{2}{c}{$\begin{array}{c}\text { Clostridium difficile episodes } \\
(1 / 5 / 2011-30 / 4 / 2012)\end{array}$} \\
\cline { 2 - 4 } Renal access type & \multicolumn{1}{c}{$N$} & $\%$ & Access class \\
\hline Unknown & 41 & & \\
Haemodialysis & 0 & & \\
$\quad$ Other & 41 & 42.3 & 44.3 \\
Arteriovenous fistula & 2 & 2.1 & \\
Arteriovenous graft & 2 & 2.1 & 49.5 \\
Non-tunnelled catheter & 46 & 47.4 & \\
Tunnelled catheter & 6 & 6.2 & 6.2 \\
$\quad$ Peritoneal dialysis & $\mathbf{1 3 8}$ & & \\
Total & $\mathbf{9 7}$ & & \\
Total known access & & & \\
\hline
\end{tabular}


Table 15.5. Centre-specific data for MSSA bacteraemia episodes by access type, $1 / 05 / 2011$ to 30/04/2012

\begin{tabular}{|c|c|c|c|c|c|c|c|c|c|c|c|}
\hline \multirow[b]{2}{*}{ Centre } & \multicolumn{3}{|c|}{ Prevalent patients on $31 / 12 / 2011$} & \multicolumn{7}{|c|}{$\begin{array}{l}\text { MSSA bacteraemia episodes } \\
(1 / 5 / 2011-30 / 4 / 2012)\end{array}$} & \multirow{2}{*}{$\begin{array}{c}\text { Rate per } 100 \\
\text { dialysis } \\
\text { patients }\end{array}$} \\
\hline & HD & PD & Dialysis & Total & AVF & AVG & NTC & TC & PD & UK & \\
\hline B Heart & 446 & 46 & 492 & 0 & 0 & 0 & 0 & 0 & 0 & 0 & 0.00 \\
\hline $\mathrm{B} \mathrm{QEH}^{*}$ & 894 & 167 & 1,061 & 10 & 4 & 0 & 0 & 6 & 0 & 0 & 0.94 \\
\hline Basldn & 155 & 26 & 181 & 1 & 0 & 0 & 0 & 1 & 0 & 0 & 0.55 \\
\hline Bristol $^{*}$ & 474 & 66 & 540 & 6 & 3 & 0 & 0 & 3 & 0 & 0 & 1.11 \\
\hline Camb* & 371 & 41 & 412 & 7 & 0 & 0 & 0 & 0 & 0 & 7 & 1.70 \\
\hline Carlis & 66 & 24 & 90 & 3 & 0 & 0 & 0 & 3 & 0 & 0 & 3.33 \\
\hline Carsh & 753 & 103 & 856 & 9 & 4 & 2 & 0 & 2 & 1 & 0 & 1.05 \\
\hline Chelms & 119 & 26 & 145 & 0 & 0 & 0 & 0 & 0 & 0 & 0 & 0.00 \\
\hline Colchr & 120 & 0 & 120 & 4 & 0 & 0 & 0 & 4 & 0 & 0 & 3.33 \\
\hline Exeter & 376 & 78 & 454 & 6 & 3 & 1 & 0 & 1 & 0 & 1 & 1.32 \\
\hline Glouc & 194 & 39 & 233 & 1 & 0 & 0 & 0 & 0 & 0 & 1 & 0.43 \\
\hline Hull & 323 & 89 & 412 & 3 & 1 & 1 & 0 & 1 & 0 & 0 & 0.73 \\
\hline Ipswi & 125 & 31 & 156 & 0 & 0 & 0 & 0 & 0 & 0 & 0 & 0.00 \\
\hline Kent & 376 & 68 & 444 & 3 & 0 & 0 & 0 & 3 & 0 & 0 & 0.68 \\
\hline L Barts* & 899 & 171 & 1,070 & 1 & 0 & 0 & 0 & 0 & 0 & 1 & 0.09 \\
\hline L Guys* & 607 & 33 & 640 & 10 & 2 & 0 & 1 & 7 & 0 & 0 & 1.56 \\
\hline L Kings & 468 & 89 & 557 & 3 & 2 & 0 & 0 & 1 & 0 & 0 & 0.54 \\
\hline L Rfree* & 711 & 94 & 805 & 18 & 6 & 1 & 0 & 10 & 0 & 1 & 2.24 \\
\hline L St.G* & 294 & 55 & 349 & 4 & 3 & 0 & 0 & 1 & 0 & 0 & 1.15 \\
\hline L West* & 1,412 & 35 & 1,447 & 20 & 0 & 0 & 1 & 19 & 0 & 0 & 1.38 \\
\hline Leeds* & 513 & 92 & 605 & 2 & 2 & 0 & 0 & 0 & 0 & 0 & 0.33 \\
\hline Oxford* & 419 & 92 & 511 & 6 & 0 & 0 & 0 & 0 & 0 & 6 & 1.17 \\
\hline Plymth* & 132 & 47 & 179 & 0 & 0 & 0 & 0 & 0 & 0 & 0 & 0.00 \\
\hline Ports* & 524 & 95 & 619 & 0 & 0 & 0 & 0 & 0 & 0 & 0 & 0.00 \\
\hline Prestn & 520 & 65 & 585 & 2 & 1 & 0 & 0 & 1 & 0 & 0 & 0.34 \\
\hline Redng & 272 & 88 & 360 & 0 & 0 & 0 & 0 & 0 & 0 & 0 & 0.00 \\
\hline Salford & 363 & 113 & 476 & 6 & 0 & 0 & 0 & 0 & 0 & 6 & 1.26 \\
\hline Sheff* & 591 & 62 & 653 & 25 & 11 & 0 & 0 & 11 & 0 & 3 & 3.83 \\
\hline Shrew & 187 & 35 & 222 & 5 & 2 & 2 & 0 & 0 & 0 & 1 & 2.25 \\
\hline Stevng & 412 & 30 & 442 & 7 & 1 & 1 & 1 & 3 & 1 & 0 & 1.58 \\
\hline Sthend & 122 & 18 & 140 & 4 & 1 & 0 & 0 & 3 & 0 & 0 & 2.86 \\
\hline Stoke & 318 & 82 & 400 & 6 & 2 & 0 & 0 & 1 & 3 & 0 & 1.50 \\
\hline Sund & 178 & 17 & 195 & 5 & 3 & 0 & 0 & 1 & 0 & 1 & 2.56 \\
\hline Truro & 152 & 26 & 178 & 4 & 2 & 0 & 0 & 2 & 0 & 0 & 2.25 \\
\hline Wirral & 196 & 42 & 238 & 3 & 0 & 0 & 0 & 0 & 0 & 3 & 1.26 \\
\hline Wolve & 307 & 71 & 378 & 8 & 4 & 0 & 0 & 3 & 1 & 0 & 2.12 \\
\hline York & 144 & 25 & 169 & 5 & 0 & 0 & 1 & 4 & 0 & 0 & 2.96 \\
\hline England & 19,371 & 3,283 & 22,654 & 261 & 74 & 11 & 5 & 113 & 6 & 52 & 1.15 \\
\hline
\end{tabular}

*Transplant centres

$\mathrm{AVF}=$ arteriovenous fistula; $\mathrm{AVG}=$ arteriovenous graft; $\mathrm{NTC}=$ non-tunnelled catheter; $\mathrm{TC}=$ tunnelled catheter; $\mathrm{PD}=$ peritoneal dialysis; $\mathrm{UK}=$ unknown access type 


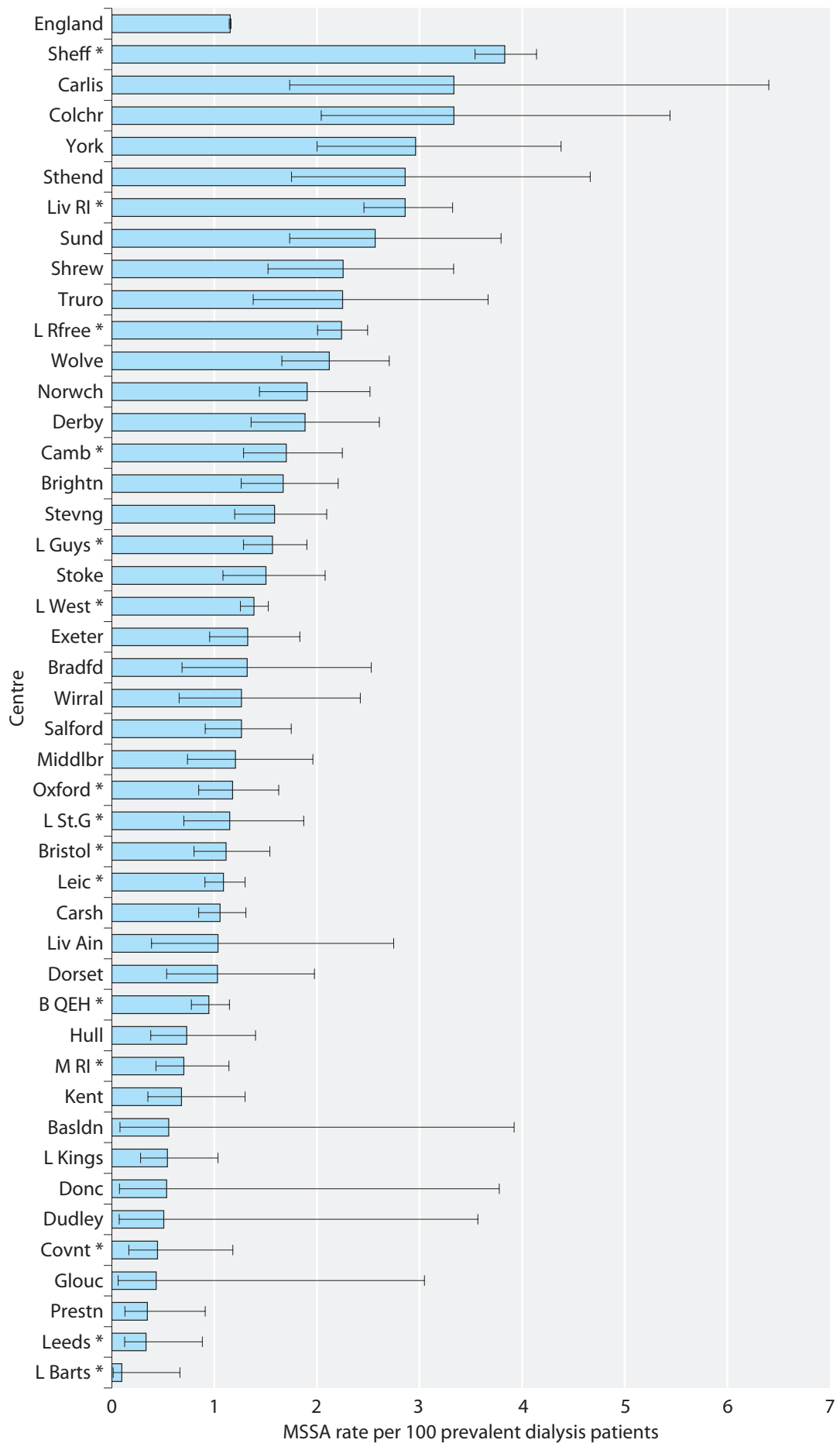

Fig. 15.6. MSSA bacteraemia rate per 100 prevalent dialysis patients per year by renal centre

Centres with no reported infection episodes are not displayed exclusions amongst the infections surveyed) with the commonest reason for exclusion being the patient was unknown to the parent centre. The number of bacteraemia episodes included totalled 191. Only eight of the records were both shared and completed by the parent centre whilst a further 96 were shared but not completed (12 of these episodes were rejected).

The overall infection rate for England was 0.92 per 100 prevalent dialysis patients per year (range 0 to 4.85) (table 15.7). As with MSSA there was considerable 


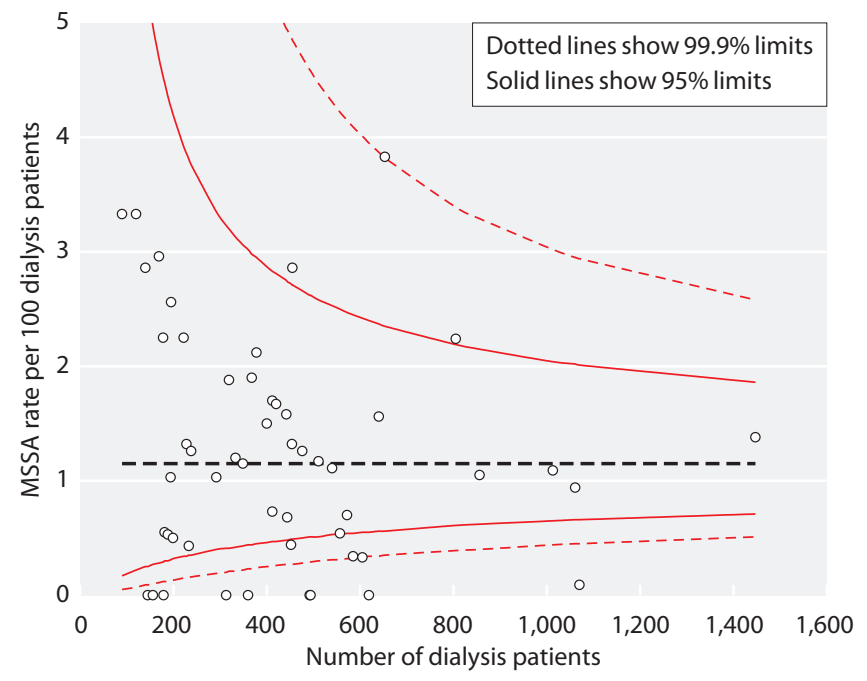

Fig. 15.7. Funnel plot of the MSSA bacteraemia rate per 100 prevalent dialysis patients per year by renal centre

variation in the bacteraemia rates between centres (figure 15.8). However, when centre size was taken into account, all the centres fell within the expected range (figure 15.9).

Amongst patients where the type of access was known, a slim majority (52.6\%) had an arteriovenous fistula as their mode of access whilst a tunnelled central venous catheter was the next most common access type (35.3\%) (table 15.8).

\section{Discussion}

The data presented are from one year of infections in ERF patients receiving dialysis that have been reported to PHE. This represents the fifth full year of reporting of MRSA BSIs in dialysis patients. These data demonstrate a further slight fall in the infection rate for MRSA in England in comparison to the report in 2011 (0.25 per 100 dialysis patients/year in 2009 vs. 0.22 per 100 dialysis patients/year in 2011). Just over half of these infections occurred in patients with a tunnelled or non-tunnelled venous catheter in comparison to patients with an arteriovenous fistula. Assuming a catheter rate of $25 \%$, this would suggest that there remains an increased risk of infection in patients with central venous access as opposed to an arteriovenous fistula. The reasons for the decline in infection rate are likely to be multifactorial. Enhanced screening programmes, attention to the care of access
Table 15.6. Type of renal access in patients with established renal failure where record shared and completed for MSSA bacteraemia episodes

\begin{tabular}{lrrc}
\hline & \multicolumn{3}{c}{$\begin{array}{c}\text { MSSA bacteraemia } \\
\end{array}$} \\
\cline { 2 - 4 } Renal access type & $N$ & $\%$ & Access class \\
\hline Unknown & 52 & & \\
Haemodialysis & & & \\
$\quad$ Other & 0 & & \\
Arteriovenous fistula & 74 & 35.4 & 40.7 \\
Arteriovenous graft & 11 & 5.3 & \\
$\quad$ Non-tunnelled catheter & 5 & 2.4 & 56.5 \\
$\quad$ Tunnelled catheter & 113 & 54.1 & \\
Perioneal dialysis & 6 & 2.9 & 2.9 \\
Total & $\mathbf{2 6 1}$ & & \\
Total known access & $\mathbf{2 0 9}$ & & \\
\hline
\end{tabular}

and reduction in the number of central venous catheters are likely to be amongst the contributing factors [6].

This report also presents the first full year of reporting of MSSA bacteraemias. There is higher incidence of MSSA bacteraemia episodes in England (compared to MRSA) with an overall infection rate of 1.15 per 100 prevalent dialysis patients per year. Again the presence of a central venous catheter confers an increased risk of MSSA bacteraemia on the patient. There was a very considerable between centre variation in terms of bacteraemia rates. These variations may be due to reporting bias because of the voluntary nature of MSSA dialysis information reporting and the fact that this is the first full year. The difference in rates between MRSA and MSSA are notable. The higher rate suggests that MSSA bacteraemia continues to be a significant issue in the dialysis population. Analyzing the discrepancy between the two rates is beyond the scope of this report but it does raise the possibility that while screening and decolonization programmes for MRSA have been successful, the reduction of MRSA strains has left patients still vulnerable to MSSA.

The first 12 months of Clostridium difficile reporting show an overall infection rate of 0.61 per 100 prevalent dialysis patients per year and once again demonstrates a degree of variation between centres. It is again worth noting that the presence of a central venous catheter appears to correlate with an increased risk of infection with nearly half of dialysis patients who recorded an episode of CDI being dialysed via a tunnelled or 
Table 15.7. Centre-specific data for Escherichia coli bacteraemia episodes by access type, 1/06/2011 to 30/04/2012

\begin{tabular}{|c|c|c|c|c|c|c|c|c|c|c|c|}
\hline \multirow[b]{2}{*}{ Centre } & \multicolumn{3}{|c|}{ Prevalent patients on $31 / 12 / 2011$} & \multicolumn{7}{|c|}{$\begin{array}{l}\text { E. coli bacteraemia episodes } \\
(1 / 6 / 2011-30 / 4 / 2012)\end{array}$} & \multirow{2}{*}{$\begin{array}{c}\text { Rate per } 100 \\
\text { dialysis } \\
\text { patients }^{\mathrm{a}}\end{array}$} \\
\hline & HD & $\mathrm{PD}$ & Dialysis & Total & AVF & AVG & NTC & TC & $\mathrm{PD}$ & UK & \\
\hline B Heart & 446 & 46 & 492 & 2 & 2 & 0 & 0 & 0 & 0 & 0 & 0.44 \\
\hline $\mathrm{B} \mathrm{QEH}^{\mathrm{b}}$ & 894 & 167 & 1,061 & 9 & 3 & 0 & 0 & 5 & 0 & 1 & 0.93 \\
\hline Basldn & 155 & 26 & 181 & 1 & 0 & 0 & 0 & 1 & 0 & 0 & 0.60 \\
\hline Bristol $^{\mathrm{b}}$ & 474 & 66 & 540 & 3 & 2 & 1 & 0 & 0 & 0 & 0 & 0.61 \\
\hline $\mathrm{Camb}^{\mathrm{b}}$ & 371 & 41 & 412 & 8 & 0 & 0 & 0 & 0 & 0 & 8 & 2.12 \\
\hline Carlis & 66 & 24 & 90 & 4 & 1 & 0 & 0 & 0 & 1 & 2 & 4.85 \\
\hline Carsh & 753 & 103 & 856 & 14 & 4 & 0 & 1 & 7 & 2 & 0 & 1.78 \\
\hline Chelms & 119 & 26 & 145 & 0 & 0 & 0 & 0 & 0 & 0 & 0 & 0.00 \\
\hline Colchr & 120 & 0 & 120 & 4 & 1 & 0 & 0 & 3 & 0 & 0 & 3.64 \\
\hline Covnt $^{\mathrm{b}}$ & 362 & 90 & 452 & 2 & 1 & 0 & 0 & 1 & 0 & 0 & 0.48 \\
\hline Exeter & 376 & 78 & 454 & 3 & 2 & 0 & 0 & 1 & 0 & 0 & 0.72 \\
\hline Glouc & 194 & 39 & 233 & 5 & 0 & 0 & 0 & 0 & 0 & 5 & 2.34 \\
\hline Hull & 323 & 89 & 412 & 4 & 4 & 0 & 0 & 0 & 0 & 0 & 1.06 \\
\hline Ipswi & 125 & 31 & 156 & 0 & 0 & 0 & 0 & 0 & 0 & 0 & 0.00 \\
\hline Kent & 376 & 68 & 444 & 5 & 3 & 0 & 0 & 2 & 0 & 0 & 1.23 \\
\hline L Barts $^{\mathrm{b}}$ & 899 & 171 & 1,070 & 1 & 0 & 0 & 0 & 0 & 0 & 1 & 0.10 \\
\hline L Guys ${ }^{b}$ & 607 & 33 & 640 & 6 & 4 & 0 & 0 & 2 & 0 & 0 & 1.02 \\
\hline L Kings & 468 & 89 & 557 & 3 & 2 & 0 & 0 & 1 & 0 & 0 & 0.59 \\
\hline L Rfree & 711 & 94 & 805 & 6 & 3 & 0 & 0 & 3 & 0 & 0 & 0.81 \\
\hline L St.G & 294 & 55 & 349 & 0 & 0 & 0 & 0 & 0 & 0 & 0 & 0.00 \\
\hline L West ${ }^{b}$ & 1,412 & 35 & 1,447 & 5 & 0 & 0 & 0 & 0 & 0 & 5 & 0.38 \\
\hline Leeds ${ }^{\mathrm{b}}$ & 513 & 92 & 605 & 11 & 7 & 1 & 0 & 3 & 0 & 0 & 1.98 \\
\hline Oxford ${ }^{\mathrm{b}}$ & 419 & 92 & 511 & 5 & 2 & 3 & 0 & 0 & 0 & 0 & 1.07 \\
\hline Plymth $^{\mathrm{b}}$ & 132 & 47 & 179 & 0 & 0 & 0 & 0 & 0 & 0 & 0 & 0.00 \\
\hline Ports ${ }^{b}$ & 524 & 95 & 619 & 1 & 0 & 0 & 0 & 1 & 0 & 0 & 0.18 \\
\hline Prestn & 520 & 65 & 585 & 9 & 5 & 0 & 0 & 2 & 1 & 1 & 1.68 \\
\hline Redng & 272 & 88 & 360 & 0 & 0 & 0 & 0 & 0 & 0 & 0 & 0.00 \\
\hline Salford & 363 & 113 & 476 & 1 & 0 & 0 & 0 & 1 & 0 & 0 & 0.23 \\
\hline Sheff $^{\mathrm{b}}$ & 591 & 62 & 653 & 8 & 3 & 0 & 1 & 3 & 1 & 0 & 1.34 \\
\hline Shrew & 187 & 35 & 222 & 3 & 2 & 0 & 0 & 0 & 0 & 1 & 1.47 \\
\hline Stevng & 412 & 30 & 442 & 6 & 2 & 0 & 0 & 4 & 0 & 0 & 1.48 \\
\hline Sthend & 122 & 18 & 140 & 4 & 3 & 0 & 0 & 1 & 0 & 0 & 3.12 \\
\hline Stoke & 318 & 82 & 400 & 0 & 0 & 0 & 0 & 0 & 0 & 0 & 0.00 \\
\hline Sund & 178 & 17 & 195 & 2 & 2 & 0 & 0 & 0 & 0 & 0 & 1.12 \\
\hline Truro & 152 & 26 & 178 & 1 & 0 & 0 & 0 & 1 & 0 & 0 & 0.61 \\
\hline Wirral & 196 & 42 & 238 & 1 & 0 & 0 & 0 & 0 & 0 & 1 & 0.46 \\
\hline Wolve & 307 & 71 & 378 & 4 & 3 & 0 & 0 & 0 & 1 & 0 & 1.15 \\
\hline York & 144 & 25 & 169 & 2 & 0 & 0 & 0 & 2 & 0 & 0 & 1.29 \\
\hline England & 19,371 & 3,283 & 22,654 & 191 & 70 & 6 & 4 & 47 & 6 & 58 & 0.92 \\
\hline
\end{tabular}

${ }^{\mathrm{a}}$ Rate per year calculated from the eleven month collection period; ${ }^{\mathrm{b}}$ Transplant centres $\mathrm{AVF}=$ arteriovenous fistula; $\mathrm{AVG}=$ arteriovenous graft; $\mathrm{NTC}=$ non-tunnelled catheter; $\mathrm{TC}=$ tunnelled catheter; $\mathrm{PD}=$ peritoneal dialysis; $\mathrm{UK}=$ unknown access type 


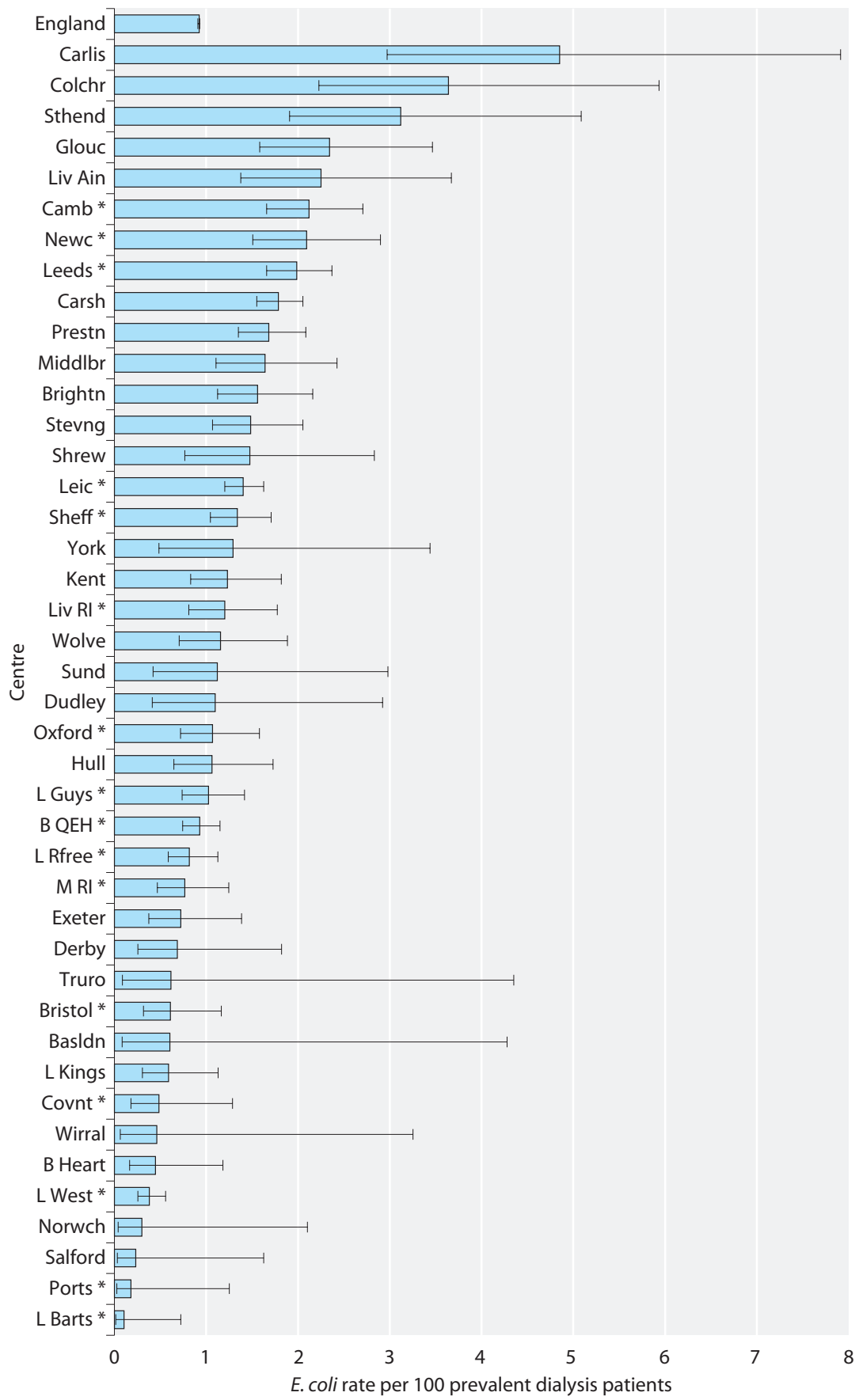

Fig. 15.8. Escherichia coli bacteraemia rate per 100 prevalent dialysis patients per year by renal centre

Centres with no reported infection episodes are not displayed non-tunnelled catheter at the time. This may underline the vulnerability to infection in this group of patients and the increased likelihood that they are exposed to courses of antibiotics.

Lastly the report also considers the first eleven months of Escherichia coli reporting (beginning in June 2011). A national system for capturing data on E. coli bacteraemia has been established in England in response to concern about recent marked increases in the number of cases [7]. However, reporting of E. coli bacteraemia in patients in ERF is relatively new and as a result there was inconsistency in reporting by microbiology laboratories and a high proportion of records were excluded due to the patient not being in or known to the allocated main centre. There were again noticable variations in infection rate between centres, although this variation should be 


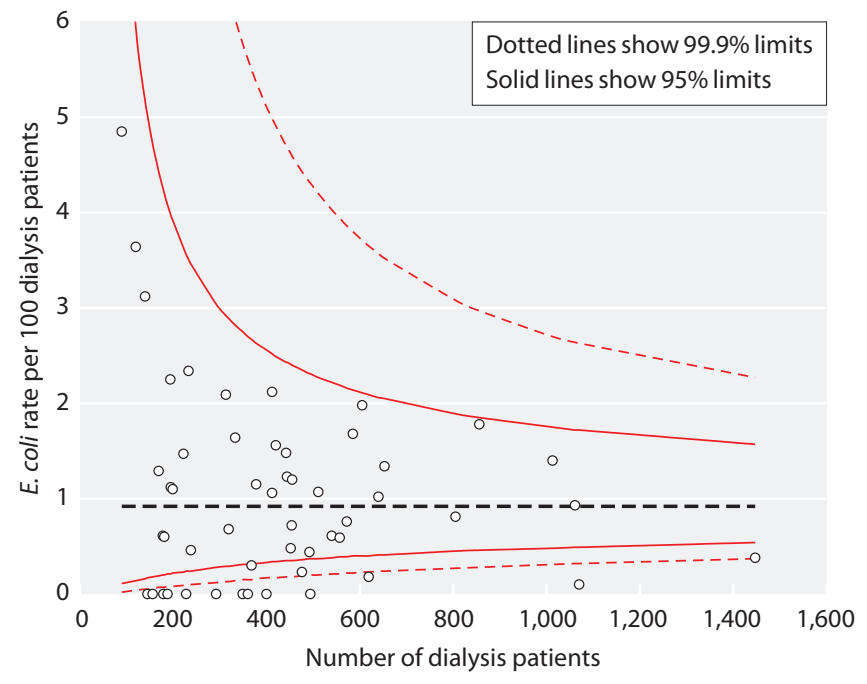

Fig. 15.9. Funnel plot of the Escherichia coli bacteraemia rate per 100 prevalent dialysis patients per year by renal centre

treated with caution because of the inconsistency in reporting. It is also worth noting that nationally, the reported rates of E. coli bacteraemia are more than three times that of MSSA so it is possible that there were a similar number of infections reported inaccurately.

It is again noticeable that a high proportion of $E$. coli infections occur in patients with a tunnelled catheter. E. coli is traditionally associated with urinary tract and other infections more than catheter related sepsis. Again this may highlight the increased vulnerability of patients reliant on lines for their dialysis access. Further work is needed over the next cycle to identify trends in

Table 15.8. Type of renal access in patients with established renal failure where record shared and completed for Escherichia coli BSI episodes

\begin{tabular}{lrrc}
\hline & \multicolumn{3}{c}{$\begin{array}{c}\text { Escherichia coli BSI } \\
(1 / 6 / 2011-30 / 4 / 2012)\end{array}$} \\
\cline { 2 - 4 } Renal access type & $N$ & $\%$ & Access class \\
\hline Unknown & 50 & & \\
Haemodialysis & 8 & & \\
Other & 70 & 52.6 & 57.1 \\
Arteriovenous fistula & 6 & 4.5 & \\
Arteriovenous graft & 4 & 3.0 & 38.3 \\
Non-tunnelled catheter & 47 & 35.3 & \\
Tunnelled catheter & 6 & 4.5 & 4.5 \\
Peritoneal dialysis & $\mathbf{1 9 1}$ & & \\
Total & $\mathbf{1 3 3}$ & & \\
Total known access & &
\end{tabular}

these infections. Increased awareness of infection reporting amongst both renal centres and microbiology units would also help to improve the robustness of this data set.

\section{Summary}

The data presented on bacteraemias occurring in ERF are as reported to Public Health England. These data demonstrate a further fall in the number and rate of MRSA bloodstream infections in England continuing the downward trend observed over the previous five years. They also show a substantial incidence of MSSA BSI in the first 12 months of reporting. Data are also included for CDI and E. coli BSI. In each infection the presence of a central venous catheter appears to confer a greater risk. Considerable regional variation is noted that may be at least partially explained by differences in reporting policies. Further work is needed to establish the overall trend in MSSA, CDI and E. coli. Finally, there is a need for consistency of reporting which would enable trends to be more clearly defined.

Conflicts of interest: none

\section{Acknowledgements}

The authors wish to acknowledge the help of our colleagues at renal centres across the country for their assistance in compiling this report.

\section{References}

1 Bray BD, Boyd J, Daly C, Donaldson K, Doyle A, Fox JG, et al. Vascular access type and risk of mortality in a national prospective cohort of haemodialysis patients. Qjm-an International Journal of Medicine. 2012;105(11):1097-1103

2 https://www.gov.uk/government/uploads/system/uploads/attachment_ data/file/215135/dh_133016.pdf

3 Fluck R, Wilson J, Tomson CRV. UK Renal Registry 12th Annual Report (December 2009): Chapter 12 Epidemiology of methicillin resistant Staphylococcus aureus Bacteraemia Amongst Patients Receiving Dialysis for Established Renal Failure in England in 2008: a joint report from the UK Renal Registry and the Health Protection Agency. Nephron Clinical Practice. 2010;115:c261-c270

4 Crowley L, Wilson J, Guy R, Pitcher D, Fluck R. UK Renal Registry 14th Annual Report: Chapter 12 Epidemiology of Staphylococcus aureus Bacteraemia Amongst Patients Receiving Dialysis for Established Renal Failure in England in 2009 to 2011: A Joint Report from the Health 
Protection Agency and the UK Renal Registry. Nephron Clinical Practice. 2012;120:c233-c245

5 Shaw C, Pruthi R, Pitcher D, Fogarty D. UK Renal Registry 15th Annual Report: Chapter 2 UK RRT Prevalence in 2011: National and CentreSpecific Analyses. Nephron Clinical Practice. 2013;123:29-54

6 Wilson J, Guy R, Elgohari S, Sheridan E, Davies J, Lamagni T, Pearson A. Trends in sources of methicillin-resistant Staphylococcus aureus (MRSA) bacteraemia: data from the national mandatory surveillance of MRSA bacteraemia in England, 2006-2009 J Hosp Infect. 2011 Nov;79(3): 211-217

7 Wilson J, Elgohari S, Livermore DM, Cookson B, Johnson A, Lamagni T, Chronias A, Sheridan E. Trends among pathogens reported as causing bacteraemia in England, 2004-2008 Clin Microbiol Infect. 2011 Mar;17(3):451-458 